\section{Mergers mean risks}

The planned merger of Glaxo and Wellcome raises questions broader than the interests of shareholders.

THE House of Commons Select Committee on Science and Technology chose a good target last week when it crossexamined Sir Richard Sykes, the chief executive of Glaxo plc, on the impact on British pharmaceutical research of his company's bid for its smaller UK rival Wellcome plc. But it then selected the wrong ammunition.

The committee was chiefly concerned with the effect of the proposed merger on jobs in research and development. It started from the view that such losses would weaken Britain's science base. What it should have asked is whether Glaxo, by staking its future on remaining a "vertically integrated" company, stretching from basic research to drug delivery, is taking an excessively high risk. The strategy contrasts with that of other companies, such as SmithKline Beecham and Merck. Its failure could have major consequences for the British pharmaceutical industry.

The answer to the question that might have been asked is "probably not". But the outcome is by no means certain. Glaxo will now depend more than ever on the ability of its research arm to find new therapeutic agents. Sykes insists that Glaxo is committed to maintaining a strong investment in both fundamental research, particularly in molecular genetics, and in the new technology for screening new agents for biological effectiveness. (The company's recent purchase of the US biotechnology company Affymax is one step in that direction.) The gamble is whether the days of serendipity are over.

If the committee had pursued that line, it would have illuminated the central paradox in the proposed merger: the claim that reducing the overall spending by Glaxo and Wellcome on research and development will actually increase the ability of the merged company to produce new products. From the outside, the logic is not self-evident, however much Glaxo argues the value of 'rationalization' (that is, cost-cutting) to justify the price it is offering for Wellcome shares. But there may be much less overlap between the two companies than some have suggested. According to Wellcome officials, there are only four research projects (out of about 80 ) in which the two companies compete directly. The major duplication is in the development phase, for example in toxicity testing. And that is where the largest staff cuts are likely to be made - and where the greatest impact of new screening technologies, such as those offered by Affymax, are likely to be felt.

The labour unions representing those working in these fields are right to be concerned about their members' job security. The argument that cuts are inevitable as the global pharmaceutical industry adjusts to unaccustomed economy will not ease the pain for those who find themselves out of work. But the argument is probably also correct. This is not a time for the faint-hearted in pharmaceuticals. Yet those who remain (including the shareholders) will properly remain nervous. Glaxo's position in the marketplace is largely due to a single product, the antiulcer drug Zantac. By staking its future on similar blockbusters, Glaxo is putting all its eggs in one basket. There may be no choice, but the select committee may regret not having asked.

\section{Derivatives sink banks}

The collapse of a British merchant bank is not a signal to ban risky trading, but an argument for transparency.

THE collapse last weekend of Barings, London's oldest merchant bank, will again raise the complaint that the money markets have become too complicated for ordinary mortals, and even banks, to understand. But that is the wrong lesson. What seems to have happened is that a young man at the bank's Singapore branch had been trading in financial instruments called 'derivatives', which are merely promises to buy or to sell at a predetermined price and at some future date an underlying commodity. In Barings' case, the commodity was the value of certain stocks on the Tokyo stock exchange. The young man seems to have committed Barings to at least $£ 600$ million of outlay in the next few weeks - a sum that exceeds the bank's capital value.

There is nothing new about derivatives. For decades, traders in Chicago have amused us with their fondness for buying parts of animals - 'pork bellies', for example - on such a basis. It is a sensible economic practice. A person knowing he needs a certain number of them in a few months will prudently pay a potential supplier a small sum of money in advance so as to secure the terms of the eventual deal. Such an arrangement will also often also suit the supplier, who may welcome knowing how much he will get for what he supplies. But equity requires that a person with an option to buy or an option to sell should be free to sell the obligation thus acquired to somebody else.

The much more common use of options now is in the management of foreign currency. A British company expecting an income in the United States by the end of 1995, and needing then to turn US dollars into sterling, may decide now to buy an option for the delivery of so much sterling at a predetermined exchange rate. If the US dollar then weakens against sterling, the anticipated income will be maintained; otherwise, the company that makes the contract will 'lose', but usually that risk takes second place besides the security the contract brings.

The real risks arise when people and organizations use the options markets as if the options were themselves commodities. The cost of an option may be a small fraction of the value of the underlying commodities. The money that changes hands is therefore a small part of the risk if things go wrong. Barings is only one of several organizations to have come unstuck in the past few months. Trading of this kind cannot be banned, for that would be inequitable. But those who gamble in this way should not do so with other people's money unless they warn them in advance, which is what shareholders (and regulators) are for. 